\title{
Critical Heat Fluxes of Subcooled Water Flow Boiling against Inlet Subcooling in Short Vertical Tube*
}

\author{
Koichi HATA ${ }^{* *}$, Hirokazu KOMORI ${ }^{* * *}$, Masahiro SHIOTSU*** and Nobuaki NODA ${ }^{* * * *}$
}

\begin{abstract}
The critical heat fluxes (CHFs) of subcooled water flow boiling for the test tube inner diameters $(d=3$ and $6 \mathrm{~mm})$ and the heated lengths $(L=67,120$ and $150 \mathrm{~mm})$ are systematically measured for the flow velocities $(u=4.0$ to $13.3 \mathrm{~m} / \mathrm{s})$, the inlet subcoolings $\left(\Delta T_{\text {sub,in }}=48\right.$ to $148 \mathrm{~K})$, the outlet subcoolings $\left(\Delta T_{\text {sub }, \text { out }}=10.5\right.$ to $\left.95.1 \mathrm{~K}\right)$, the inlet pressure $\left(P_{\text {in }}=753\right.$ to $995 \mathrm{kPa})$ and the outlet pressure $\left(P_{\text {out }}=720\right.$ to $\left.887 \mathrm{kPa}\right)$. The SUS304 tubes of $L=67,120$ and $150 \mathrm{~mm}$ for $d=3 \mathrm{~mm}$ and $L=150 \mathrm{~mm}$ for $d=6 \mathrm{~mm}$ are used. The values of $L / d$ are 22, 40 and 50 for $d=3 \mathrm{~mm}$, and 25 for $d=6 \mathrm{~mm}$, respectively. The CHFs, $q_{c r, s u b}$, for a fixed $\Delta T_{\text {sub,out }}$ become gradually lower with an increase in the $L / d$ in the whole experimental range. The CHF correlation against outlet subcooling, which has been previously derived for $L / d$ lower than 16, was modified to new one containing the $L / d$ effect based on these experimental data. Furthermore, the relation between $q_{c r, s u b}$ and $L / d$ for a fixed $\Delta T_{\text {sub,in }}$ was checked. The values of $q_{c r, s u b}$ for a fixed $\Delta T_{\text {sub,in }}$ became exponentially lower with the increase in $L / d$. CHF correlation against inlet subcooling has been given based on the experimental data for $L / d$ ranging from 4.08 to 50 . The correlations against outlet and inlet subcoolings can describe not only the CHFs obtained in this work for the inner diameter of 3 and $6 \mathrm{~mm}$ at the outlet pressure of around $800 \mathrm{kPa}$ but also the authors' published CHFs data (1611 points) for the wide ranges of $P_{i n}=159 \mathrm{kPa}$ to $1 \mathrm{MPa}, d=3$ to $12 \mathrm{~mm}, L=33$ to $150 \mathrm{~mm}$ and $u=4.0$ to $13.3 \mathrm{~m} / \mathrm{s}$ within $15 \%$ difference for $30 \mathrm{~K} \leq \Delta T_{\text {sub,out }} \leq 140 \mathrm{~K}$ and $40 \mathrm{~K} \leq \Delta T_{\text {sub,in }} \leq 151 \mathrm{~K}$.
\end{abstract}

Key Words: Critical Heat Flux, Subcooled Flow Boiling, Inlet Subcooling, Short Vertical Tube

\section{Introduction}

The knowledge of the critical heat fluxes (CHFs) of subcooled water flow boiling in short vertical tube is important for the design of a divertor in a nuclear fusion facility. We have already measured the CHFs, $q_{c r, s u b}$, for wide range of experimental conditions to establish the database for designing the divertors for a helical type fusion experimental device, which is Large Helical Device (LHD) lo-

* Received 22nd October, 2003 (No. 03-4146)

** Institute of Advanced Energy, Kyoto Univ., Gokasho, Uji, Kyoto 611-0011, Japan. E-mail: hata@iae.kyoto-u.ac.jp

*** Dept. of Energy Science and Technology, Kyoto University, Gokasho, Uji, Kyoto 611-0011, Japan.

E-mail: komori@pe.energy.kyoto-u.ac.jp, shiotsu@ uji.energy.kyoto-u.ac.jp

**** National Institute for Fusion Science, 322-6 Oroshi-cho, Toki, Gifu 509-5292, Japan.

E-mail: noda@LHD.nifs.ac.jp cated in National Institute for Fusion Science, Japan ${ }^{(1)-(5)}$. And, we have given the CHF correlation against average outlet subcoolings based on the experimental data for four different test tubes with inner diameters, $d$, of 3, 6, 9 and $12 \mathrm{~mm}$ and heated lengths, $L$, of 33, 67, 99 and $133 \mathrm{~mm}$ respectively with $L / d=11$.

$$
\begin{aligned}
B o= & 0.069\left\{\frac{d}{\sqrt{\sigma / g\left(\rho_{l}-\rho_{g}\right)}}\right\}^{-0.1} W e^{-0.3} S c^{0.7} \\
& \text { for outlet subcooling }
\end{aligned}
$$

where, $S c$ is non-dimensional outlet subcooling, $S c=$ $c_{p l}\left(\Delta T_{\text {sub,out }}\right)_{\text {cal }} / h_{f g}$. The correlation can describe the authors' published CHFs for the wide range of $P_{\text {out }}=$ $159 \mathrm{kPa}$ to $1 \mathrm{MPa}, d=3,6,9$ and $12 \mathrm{~mm}, L=49,99$ and $149 \mathrm{~mm}, L / d=4.08$ to $16.56,\left(\Delta T_{\text {sub,out }}\right)_{\text {cal }}=-4$ to $130 \mathrm{~K}$ and $u=4.0$ to $13.3 \mathrm{~m} / \mathrm{s}$ within $15 \%$ difference for $50 \mathrm{~K} \leq\left(\Delta T_{\text {sub,out }}\right)_{\text {cal }} \leq 130 \mathrm{~K}$ and within -10 to $+30 \%$ for $30 \mathrm{~K}<\left(\Delta T_{\text {sub,out }}\right)_{\text {cal }}<50 \mathrm{~K}$.

The objectives of present study are threefold. First is 
to measure the CHFs on inner side of a pipe with combinations of inner diameter $(d=3$ and $6 \mathrm{~mm})$ and tube length ( $L=67,120$ and $150 \mathrm{~mm}$ ) for wide ranges of flow velocity and inlet subcooling with $22 \leq L / d \leq 50$. Second is to confirm the applicability of the CHF correlation against outlet subcooling, Eq. (1), to the experimental data of $q_{c r}$ for $22 \leq L / d \leq 50$. Third is to derive the CHF correlation against inlet subcooling based on these experimental data, because it is more convenient to use for designing a divertor.

\section{Nomenclature}

Bo $:=q_{c r} / G h_{f g}$, boiling number

$c_{p}$ : specific heat at constant pressure, $\mathrm{J} / \mathrm{kg} \mathrm{K}$

$d:$ test tube inner diameter, $\mathrm{m}$

$G:=\rho_{l} u$, mass flux, $\mathrm{kg} / \mathrm{m}^{2} \mathrm{~s}$

$g:$ acceleration of gravity, $\mathrm{m} / \mathrm{s}^{2}$

$h_{f g}:$ latent heat of vaporization, $\mathrm{J} / \mathrm{kg}$

$L$ : heated length, $\mathrm{m}$

$L_{e}:$ entrance length, $\mathrm{m}$

$L_{i p t}$ : distance between inlet pressure transducer and inlet of the heated length, $\mathrm{m}$

$P_{\text {in }}:$ pressure at inlet of heated length, $\mathrm{kPa}$

$P_{i p t}$ : pressure measured by inlet pressure transducer, $\mathrm{kPa}$

$P_{\text {out }}:$ pressure at outlet of heated length, $\mathrm{kPa}$

$\left(P_{\text {out }}\right)_{\text {cal }}:$ calculated outlet pressure, $\mathrm{kPa}$

$P_{\text {opt }}$ : pressure measured by outlet pressure transducer, $\mathrm{kPa}$

$Q_{0}$ : initial exponential heat input, $\mathrm{W} / \mathrm{m}^{2}$

$q$ : heat flux, $\mathrm{W} / \mathrm{m}^{2}$

$q_{c r, s u b}$ : critical heat flux for subcooled condition, $\mathrm{W} / \mathrm{m}^{2}$

$R e:=G d / \mu_{l}$, Reynolds number

$S c:=c_{p l}\left(\Delta T_{\text {sub,out }}\right)_{c a l} / h_{f g},=c_{p l} \Delta T_{\text {sub,out }} / h_{f g}$, nondimensional outlet subcooling

$S c^{*}:=c_{p l} \Delta T_{s u b, i n} / h_{f g}$, non-dimensional inlet subcooling

$t:$ time, $\mathrm{s}$

$T_{\text {in }}:$ inlet liquid temperature, $\mathrm{K}$

$T_{\text {out }}$ : outlet liquid temperature, $\mathrm{K}$

$T_{s}$ : heater inner surface temperature, $\mathrm{K}$

$\left(T_{\text {out }}\right)_{\text {cal }}$ : calculated outlet liquid temperature, $\mathrm{K}$

$T_{\text {sat }}$ : saturation temperature, $\mathrm{K}$

$T_{\text {sat,out }}$ : outlet saturation temperature, $\mathrm{K}$

$\Delta T_{\text {sub,in }}:=\left(T_{\text {sat }}-T_{\text {in }}\right)$, inlet liquid subcooling, $\mathrm{K}$

$\Delta T_{\text {sub,out }}:=\left(T_{\text {sat }}-T_{\text {out }}\right)$, outlet liquid subcooling, $\mathrm{K}$

$\left(\Delta T_{\text {sub,out }}\right)_{\text {cal }}$ : calculated outlet liquid subcooling, $\mathrm{K}$

$u$ : flow velocity, $\mathrm{m} / \mathrm{s}$

$W e:=G^{2} d / \rho_{l} \sigma$, Weber number

$\lambda$ : friction factor for smooth tube

$\rho:$ density, $\mathrm{kg} / \mathrm{m}^{3}$

$\sigma:$ surface tension, $\mathrm{N} / \mathrm{m}$

$\tau$ : exponential period, $\mathrm{s}$

Superscript

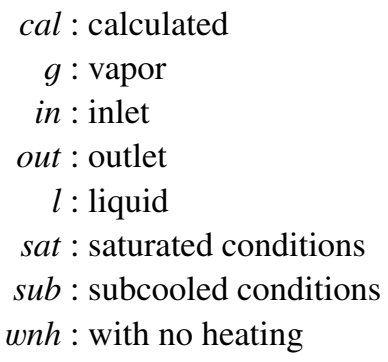

\section{Experimental Apparatus and Method}

The schematic diagram of experimental water loop is shown in Fig. 1. The loop is made of SUS304 stainless steel and is capable of working up to $2 \mathrm{MPa}$. The loop has four test sections whose inner diameters are 3, 6, 9 and $12 \mathrm{~mm}$. Test sections were vertically oriented with water flowing upward. Two test sections of the inner diameter of 3 and $6 \mathrm{~mm}$ were used in this work. The circulating water was distilled and deionized with about 5-M $\Omega \mathrm{cm}$ specific resistivity. The circulating water through the loop was heated or cooled to keep a desired inlet temperature by pre-heater or cooler. The flow velocity was measured by a mass flow meter using a vibration tube. The flow velocity was controlled by regulating the frequency of the three-phase alternating power source to the canned type circulation pump. The water was pressurized by nitrogen gas. The pressure at the inlet of the test tube was controlled within $\pm 1 \mathrm{kPa}$ of a desired value by using a pressure controller. The cross-sectional view of 3-mm inner diameter test section used in this work is typically shown in Fig. 2. The rough inner surface was fabricated by annealing the test tubes first in the air and was then acidized. The rough inner surface test tube was used as a standard one. The test tube was reinforced with the heat-shrink Teflon tube because the test tube wall was too thin for high pressure experiment. Wall thickness of the test tubes was $0.5 \mathrm{~mm}$. The silver-coated 5 -mm thickness copperelectrode-plates to supply heating current were soldered

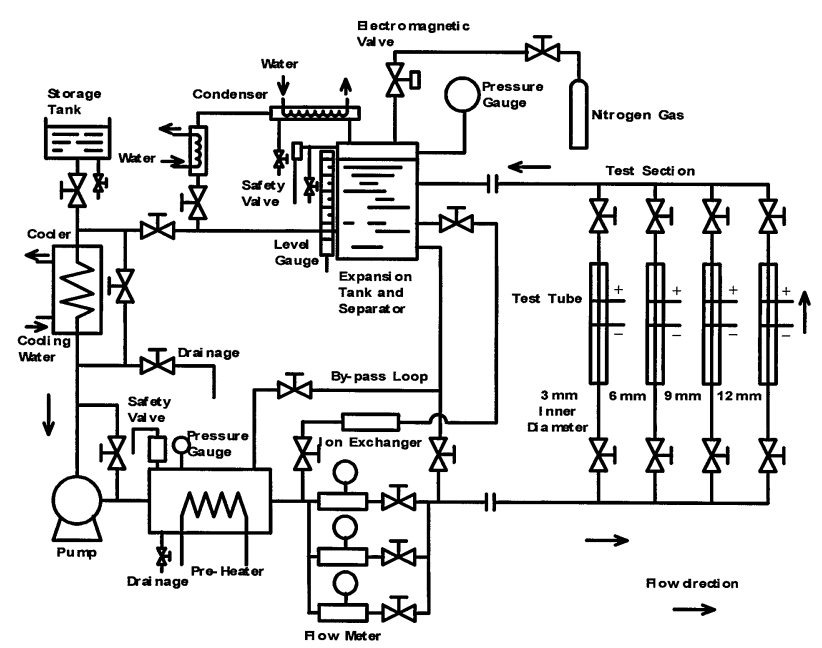

Fig. 1 Schematic diagram of experimental apparatus 


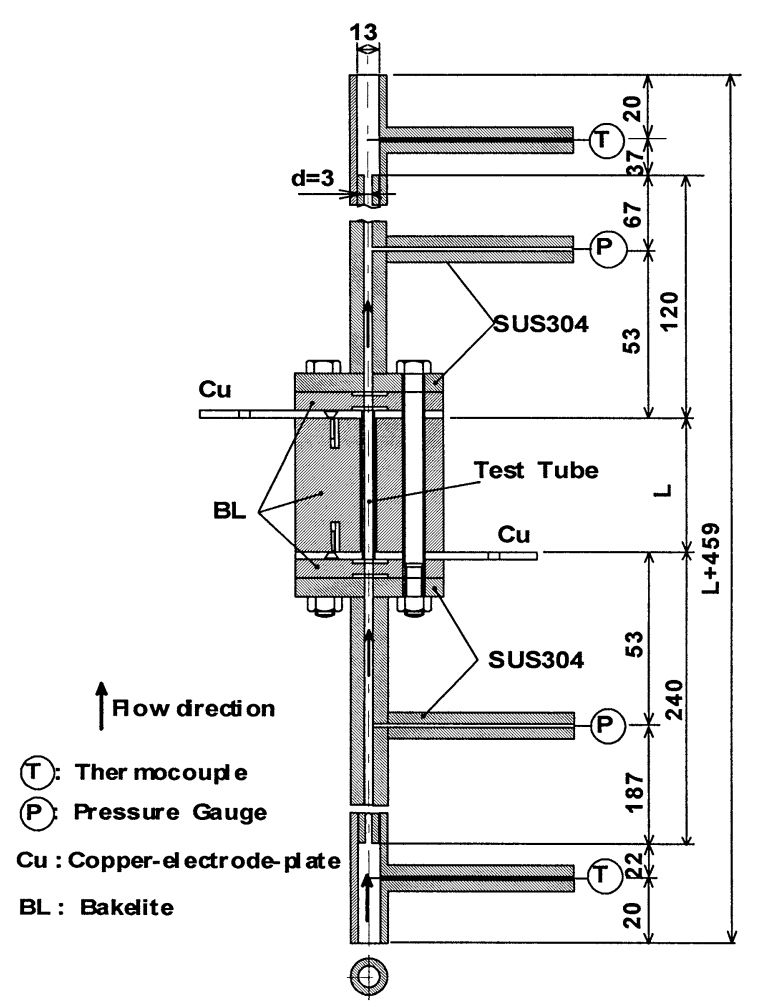

Fig. 2 Vertical cross-sectional view of 3-mm inner diameter test section

on the surfaces of the both ends of the test tube. The both ends of test tube were electrically isolated from the loop by Bakelite plates of 14-mm thickness. The test tube was also thermally insulated from atmosphere with a Bakelite block of $120 \mathrm{~mm}$ wide, $80 \mathrm{~mm}$ deep and $L \mathrm{~mm}$ high. The test tube was heated with a steadily increasing current supplied from a direct current source (DC $3000 \mathrm{~A}, 35 \mathrm{~V}$ ). The $\mathrm{CHF}, q_{c r, s u b}$, was realized by a steadily increasing heat input to the test tube. At the CHF, the test tube average temperature rapidly increases. The current for the heat input to the test tube was automatically cut off when the measured average temperature increased up to the preset temperature, which was somewhat higher than corresponding CHF surface temperature. This procedure avoided the actual burnout of the test tube.

The transient average temperature of the test tube was measured with resistance thermometry participating as a branch of a double bridge circuit for the temperature measurement. The output voltage from the bridge circuit together with the voltage drops across the two electrodes and across a standard resistance were amplified and then were sent via a D/A converter to a digital computer. These voltages were simultaneously sampled at a constant time interval ranging from 60 to $200 \mu$ s. The average temperature of the test tube was calculated with the aid of previously calibrated resistance-temperature relation. The heat generation rate in the test tube was calculated from the measured voltage difference between the potential taps of the test tube and the standard resistance. The surface heat flux is the difference between the heat generation rate per unit surface area and the rate of change of energy storage in the test tube obtained from the faired average temperature versus time curve. The inner surface temperature was also obtained by solving the heat conduction equation in the test tube under the conditions of measured average temperature and heat generation rate of the test tube.

In case of the 3-mm inner diameter test section, before entering the test tube, the test water flows through the tube with the same inner diameter of the test tube to form the fully developed velocity profile. The entrance tube length is given $240 \mathrm{~mm}\left(L_{e} / d=80\right)$. Details are shown in Appendix. The inlet and outlet liquid temperatures were measured by 1-mm o.d., sheathed, K-type thermocouples which are located at the centerline of the tube at the upper and lower stream points of 262 and $157 \mathrm{~mm}$ from the tube inlet and outlet points. The tube inner diameter at the measuring points is enlarged from 3-mm inner diameter to 13$\mathrm{mm}$ inner diameter to assure that superheated test water is perfectly mixing. The inlet and outlet pressures were measured by the strain gauge transducers, which were located near the entrance of conduit at upper and lower stream points of $53 \mathrm{~mm}$ from the tube inlet and outlet points. The thermocouples and the transducers were installed in the conduits as shown in Fig. 2. The inlet and outlet pressures for $d=3 \mathrm{~mm}$ were calculated from the pressures measured by inlet and outlet pressure transducers as follows,

$$
\begin{aligned}
& P_{\text {in }}=P_{i p t}-\left\{\left(P_{i p t}\right)_{w n h}-\left(P_{\text {opt }}\right)_{w n h}\right\} \times \frac{0.053}{0.106+L} \\
& P_{\text {out }}=P_{\text {in }}-\left(P_{\text {in }}-P_{\text {opt }}\right) \times \frac{L}{0.053+L}
\end{aligned}
$$

Experimental errors are estimated to be $1 \mathrm{~K}$ in inner tube surface temperature and $\pm 2 \%$ in heat flux. Inlet flow velocity, inlet and outlet subcoolings, and inlet and outlet pressures were measured within the accuracy $\pm 2 \%, \pm 1 \mathrm{~K}$ and $\pm 1 \mathrm{kPa}$ respectively.

\section{Experimental Results and Discussion}

\subsection{Experimental conditions}

The initial experimental conditions such as inlet flow velocity, inlet subcooling and inlet pressure for the flow boiling CHF experiments were determined independently each other before each experimental run.

The experimental conditions were as follows:

Heater Material 304 stainless steel

Surface Condition Rough surface (commercial)

Inner Diameter $(d) \quad 3$ and $6 \mathrm{~mm}$

Heated Length $(L) \quad 67,120$ and $150 \mathrm{~mm}$ for $d=$ $3 \mathrm{~mm}$

$150 \mathrm{~mm}$ for $d=6 \mathrm{~mm}$

$L / d \quad 22,40$ and 50 for $d=3 \mathrm{~mm}$

25 for $d=6 \mathrm{~mm}$

Wall Thickness $0.5 \mathrm{~mm}$ 


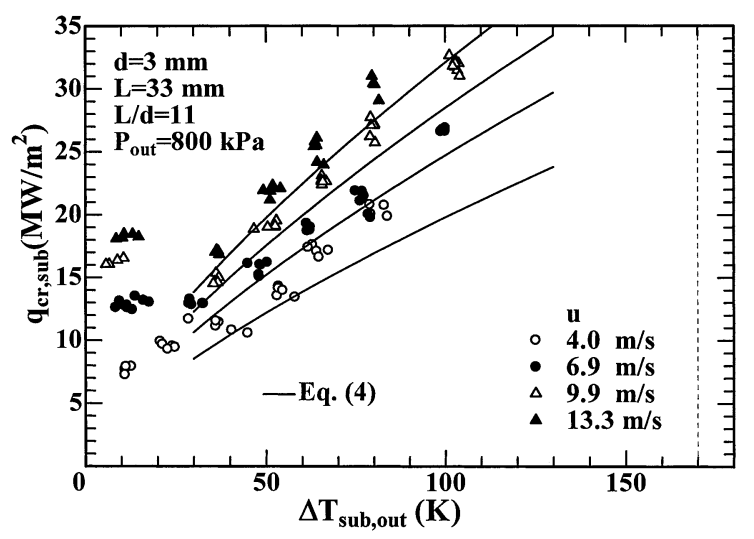

Fig. $3 q_{c r, s u b}$ vs. $\Delta T_{\text {sub,out }}$ for an inner diameter of $3 \mathrm{~mm}$ with a heated length of $33 \mathrm{~mm}$ at an outlet pressure of $800 \mathrm{kPa}$

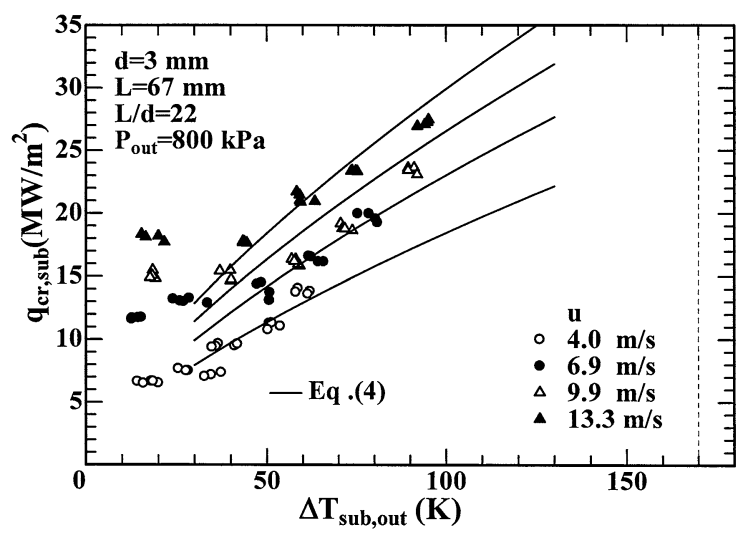

Fig. $4 q_{c r, \text { sub }}$ vs. $\Delta T_{\text {sub,out }}$ for an inner diameter of $3 \mathrm{~mm}$ with a heated length of $67 \mathrm{~mm}$ at an outlet pressure of $800 \mathrm{kPa}$

Inlet flow velocity $(u) \quad 4.0,6.9,9.9$ and $13.3 \mathrm{~m} / \mathrm{s}$

Inlet Pressure $\left(P_{\text {in }}\right) \quad 753-995 \mathrm{kPa}$

Outlet Pressure $\left(P_{\text {out }}\right) \quad 720-887 \mathrm{kPa}$

Inlet Subcooling $\left(\Delta T_{\text {sub,in }}\right) \quad 48-148 \mathrm{~K}$

Outlet Subcooling $\left(\Delta T_{\text {sub,out }}\right) \quad 10.5-95.1 \mathrm{~K}$

Inlet Liquid Temperature $295-395 \mathrm{~K}$

Steadily Increasing Heat Input $Q_{0} \exp (t / \tau), \tau=10$, 20 and $33.3 \mathrm{~s}$

\subsection{CHF against outlet subcooling}

The CHFs, $q_{c r, s u b}$, for the inner diameter of $3 \mathrm{~mm}$ with $L=33,67,120$ and $150 \mathrm{~mm}$ at the outlet pressure of around $800 \mathrm{kPa}$ are shown versus the outlet subcoolings measured, $\Delta T_{\text {sub,out }}$, with the flow velocities of 4.0, 6.9, 9.9 and $13.3 \mathrm{~m} / \mathrm{s}$ in Figs. 3 to 6, respectively. The outlet subcooling, $\Delta T_{\text {sub,out }}$, averaged over the cross sectional area was obtained from the measured outlet liquid temperature, $T_{\text {out }}$, and outlet pressure, $P_{\text {out }}$. The CHFs become higher with an increase in flow velocity at a fixed $\Delta T_{\text {sub,out }}$. These figures illustrate the trends in the variation of CHF with increasing outlet subcooling. The CHFs first decrease to the minimum $\mathrm{CHF}$ at the $\Delta T_{\text {sub,out }}$ of around $30 \mathrm{~K}$, and then increase with an increase in $\Delta T_{\text {sub,out }}$. The increasing rate becomes lower for higher $\Delta T_{\text {sub,out }}$. These

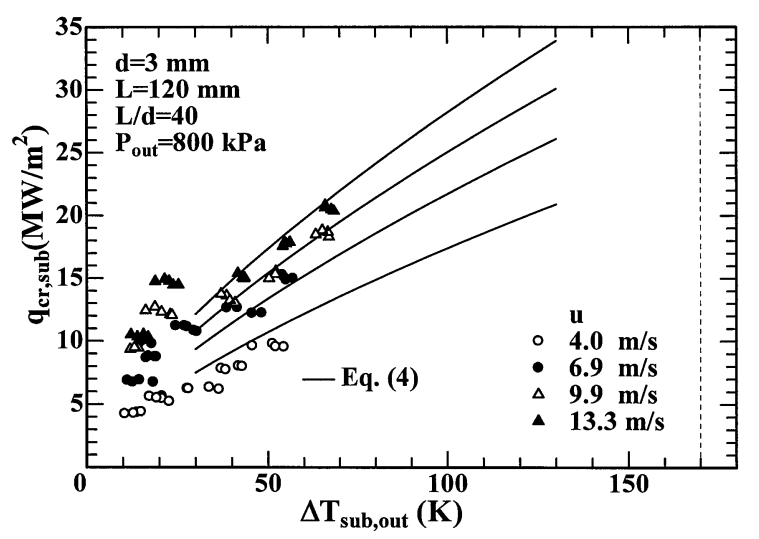

Fig. $5 q_{c r, s u b}$ vs. $\Delta T_{\text {sub,out }}$ for an inner diameter of $3 \mathrm{~mm}$ with a heated length of $120 \mathrm{~mm}$ at an outlet pressure of $800 \mathrm{kPa}$

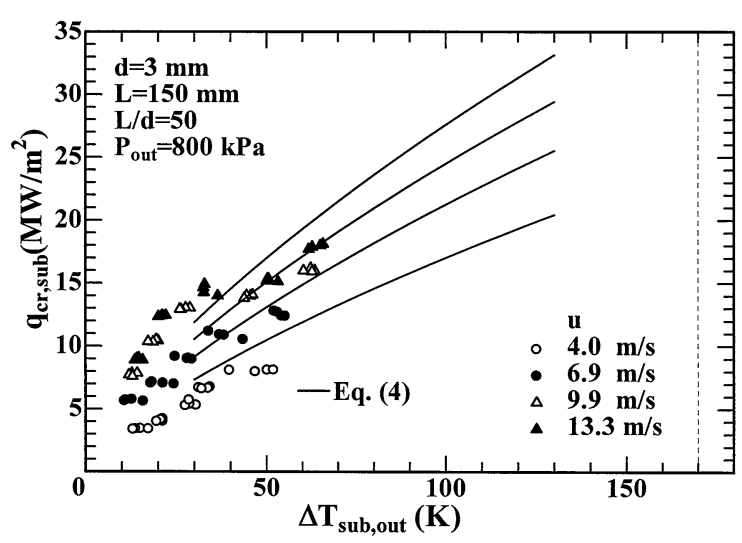

Fig. $6 q_{c r, s u b}$ vs. $\Delta T_{\text {sub,out }}$ for an inner diameter of $3 \mathrm{~mm}$ with a heated length of $150 \mathrm{~mm}$ at an outlet pressure of $800 \mathrm{kPa}$

trends have been already reported by Hata, et al. ${ }^{(1),(2)}$ on $\mathrm{CHF}$ data for the heated length of $50 \mathrm{~mm}$ with the inner diameters of 6,9 and $12 \mathrm{~mm}$.

It is assumed that, in the first low subcooling range, flushing-like phenomenon due to the vapor bubbles from inner side of a small diameter tube may be occurring and inducing the increase of flow velocity through the reduction in macroscopic density of two-phase mixture. The enhancement of CHF by this mechanism will become insignificant with the increase of subcooling. It is likely that the first low subcooling range would become narrower by using a larger diameter test tube. More detailed study on the CHFs in the first low subcooling range for a vertical short tube will appear in the near future.

3.2.1 Influence of $\boldsymbol{L} / \boldsymbol{d} \quad$ Figures 7 to 10 show the influence of $L / d$ on the CHF for inner diameters of 3,6 , 9 and $12 \mathrm{~mm}$ at $\Delta T_{\text {sub,out }}$, of $50,70,90$ and $90 \mathrm{~K}$ respectively. The $q_{c r, s u b}$ for the $L / d$ ranging from 4.08 to 50 were shown versus the $L / d$ with the flow velocity as a parameter. The CHFs become linearly lower with the increase in the $L / d$. The slope of each curve on the log-log graph is almost constant about -0.1 except that for the flow velocity of $4.0 \mathrm{~m} / \mathrm{s}$ in Fig. 7 , although it has been reported 


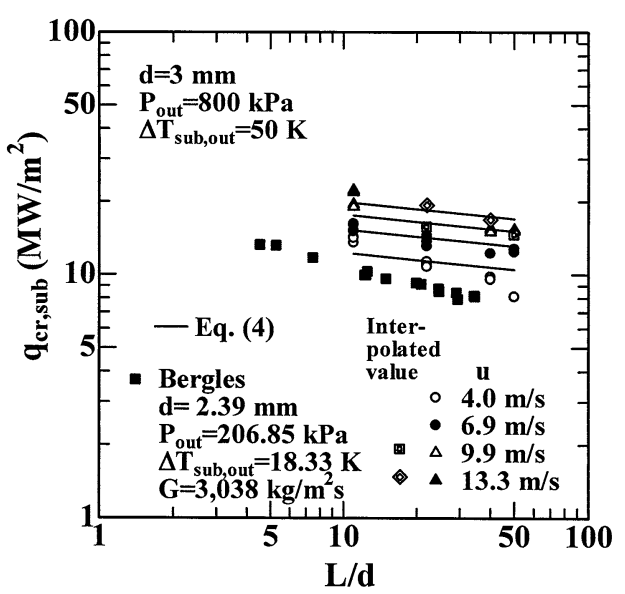

Fig. $7 q_{c r, s u b}$ vs. $L / d$ for an inner diameter of $3 \mathrm{~mm}$ at $\Delta T_{\text {sub,out }}$ of $50 \mathrm{~K}$ with the flow velocity of $4.0,6.9,9.9$ and $13.3 \mathrm{~m} / \mathrm{s}$

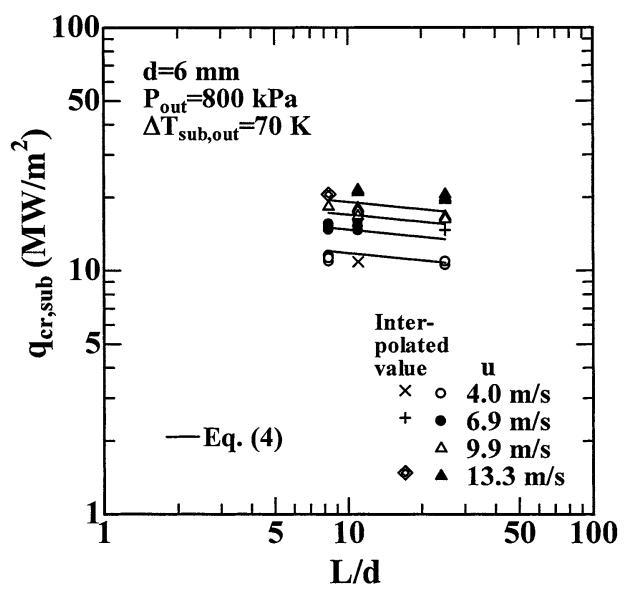

Fig. $8 q_{c r, s u b}$ vs. $L / d$ for an inner diameter of $6 \mathrm{~mm}$ at $\Delta T_{\text {sub,out }}$ of $70 \mathrm{~K}$ with the flow velocity of $4.0,6.9,9.9$ and $13.3 \mathrm{~m} / \mathrm{s}$

that the CHFs are independent $L / d$ of in the range of $L / d$ larger than $40^{(6)}$. Furthermore, the slope for $u=4.0 \mathrm{~m} / \mathrm{s}$ in the figure is about -0.25 . The trend of $(L / d)^{-0.25}$ dependence under this experimental condition can also be seen for the experimental data by Bergles ${ }^{(7)}$. It is supposed that the bubble boundary layer under subcooled condition become thicker along the heated length of the test tube and further, the thickness become especially larger in comparison with the vapor bubble diameter at low flow velocity with small tube inner diameter.

\subsubsection{CHF correlation It has been clarified that} the $q_{c r, s u b}$ against $\Delta T_{\text {sub,out }}$ for a fixed $L / d$ are almost proportional to $d^{-0.4}, u^{0.4}$ and $\left(\Delta T_{\text {sub,out }}\right)^{0.7}$ for $\Delta T_{\text {sub,out }} \geq$ $30 \mathrm{~K}$. The CHF correlation against outlet subcooling, Eq. (1), has been derived ${ }^{(5)}$. In this work, the $q_{c r, s u b}$ are also proportional to $(L / d)^{-0.1}$ except for the experimental data at $u=4.0 \mathrm{~m} / \mathrm{s}$ for $d=3 \mathrm{~mm}$, as mentioned above. The existing CHF correlation against outlet subcooling, Eq. (1), was modified to new one containing the $L / d$ effect

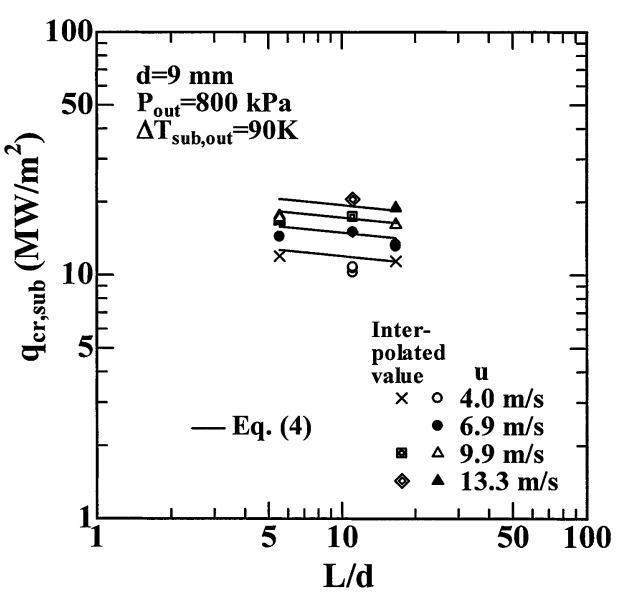

Fig. $9 q_{c r, s u b}$ vs. $L / d$ for an inner diameter of $9 \mathrm{~mm}$ at $\Delta T_{\text {sub,out }}$ of $90 \mathrm{~K}$ with the flow velocity of $4.0,6.9,9.9$ and $13.3 \mathrm{~m} / \mathrm{s}$

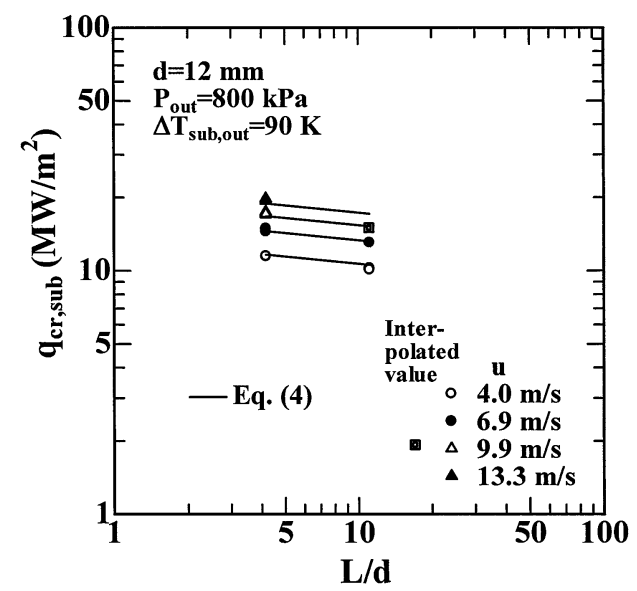

Fig. $10 q_{c r, s u b}$ vs. $L / d$ for an inner diameter of $12 \mathrm{~mm}$ at $\Delta T_{\text {sub,out }}$ of $90 \mathrm{~K}$ with the flow velocity of 4.0, 6.9, 9.9 and $13.3 \mathrm{~m} / \mathrm{s}$

as follows based on these experimental data for wide $L / d$ range from 4.08 to 50 clarified in this work.

$$
B o=0.082\left\{\frac{d}{\sqrt{\sigma / g\left(\rho_{l}-\rho_{g}\right)}}\right\}^{-0.1} W e^{-0.3}\left(\frac{L}{d}\right)^{-0.1} S c^{0.7}
$$

for outlet subcooling $\left(\Delta T_{\text {sub,out }} \geq 30 \mathrm{~K}\right)$

where, $S c$ is non-dimensional outlet subcooling, $S c=$ $c_{p l} / \Delta T_{\text {sub,out }} / h_{f g}$. Saturated thermo-physical properties were evaluated at the outlet pressure.

The curves given by Eq. (4) at each flow velocity are shown in Figs. 3 to 10 for comparison. The CHF data for $\Delta T_{\text {sub,out }} \geq 30 \mathrm{~K}$ are in good agreement with the values given by the correlation. Equation (4) was derived based on the experimental data at the outlet pressure of $800 \mathrm{kPa}$. Besides the experimental data obtained in this work, we have already reported the CHFs (1611 points) for the wide range of $P_{\text {out }}=159 \mathrm{kPa}$ to $1 \mathrm{MPa}, d=3,6,9$ and $12 \mathrm{~mm}, L=33$ to $150 \mathrm{~mm}, \Delta T_{\text {sub,out }}=-4$ to $130 \mathrm{~K}$ and $u=4.0$ to $13.3 \mathrm{~m} / \mathrm{s}^{(1)-(5)}$. To confirm the applicability of 


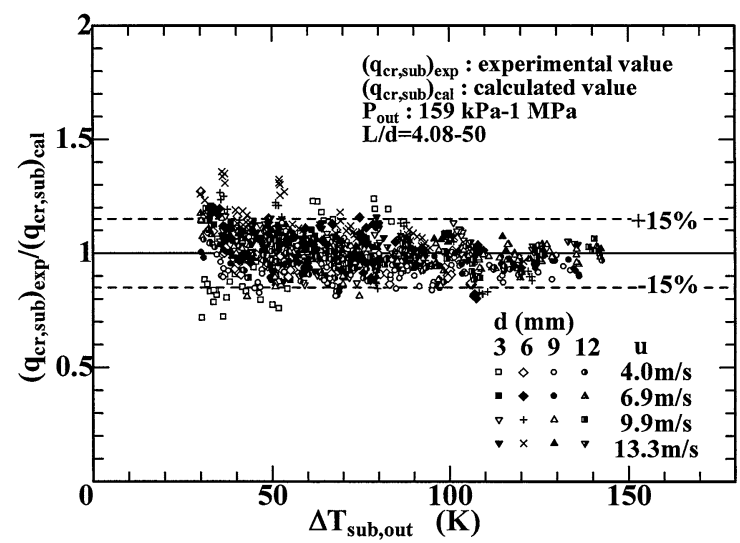

Fig. 11 Ratio of CHF data for the inner diameter of 3, 6, 9 and $12 \mathrm{~mm}$ to the values derived from the outlet CHF correlation versus $\Delta T_{\text {sub,out }}$ at outlet pressures of $159 \mathrm{kPa}-$ $1 \mathrm{MPa}$

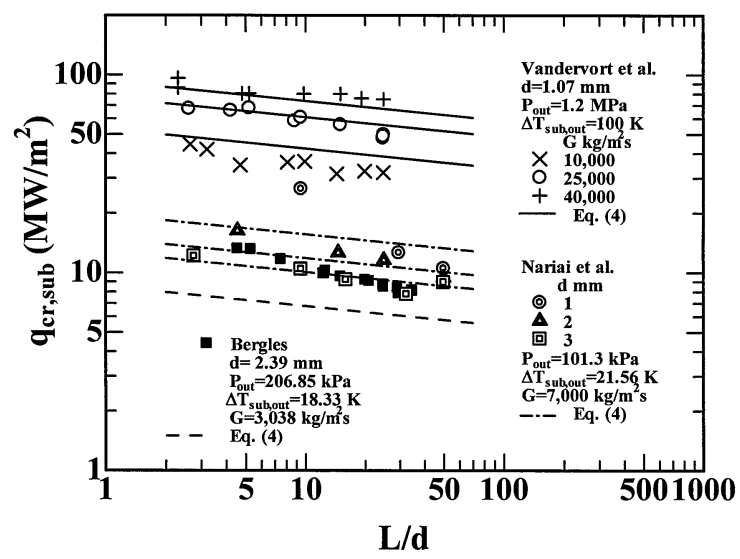

Fig. 12 Comparison of the values derived from the outlet CHF correlation with other workers' CHF data

Eq. (4) to the data for wide range of pressures, the ratios of these CHF data to the corresponding values calculated by Eq. (4) are shown versus $\Delta T_{\text {sub,out }}$ in Fig. 11. Most of the data are within $\pm 15 \%$ for $30 \mathrm{~K} \leq \Delta T_{\text {sub }, \text { out }} \leq 140 \mathrm{~K}$.

\subsubsection{Comparison of our correlation with other} workers' CHF data The values derived from the correlation against the outlet subcooling are compared with other workers' experimental data ${ }^{(7)-(9)}$ with $d, P_{\text {out }}$, $\Delta T_{\text {sub,out }}$ and $G$ as a parameter in Fig. 12. The experimental data for $d=1.07 \mathrm{~mm}$ by Vandervort et al. are in good agreement with the values given by the correlation in the whole experimental range. Those for $d=2$ and $3 \mathrm{~mm}$ by Nariai et al. show nearly the same trend of dependence on the values derived from the correlation, although the $q_{c r, s u b}$ for $d=1 \mathrm{~mm}$ are proportional to $(L / d)^{-0.54}$ and the experimental data point for $L / d=10$ is far higher than the value given by the correlation. Those by Bergles are 1.78 to 1.35 times as large as the correlation in the whole experimental range. And furthermore, it is confirmed that the decreasing rate of the $q_{c r \text { sub }}$ is a little smaller than that for the correlation, as mentioned above.

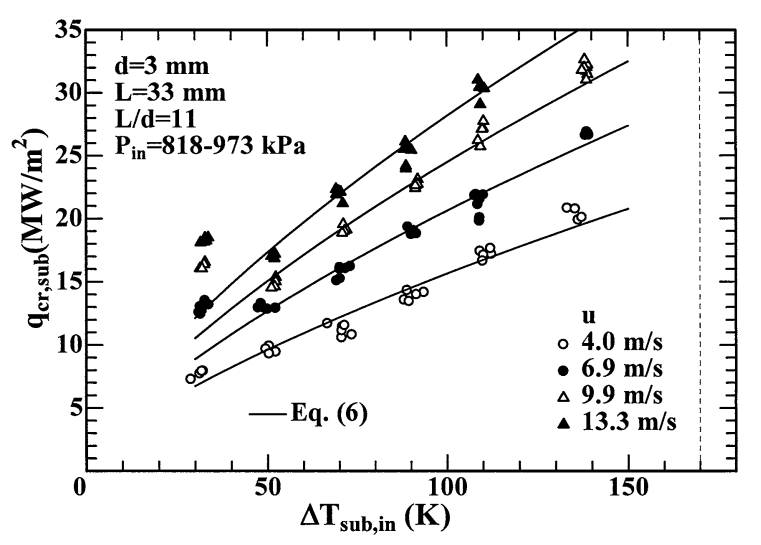

Fig. $13 q_{c r, s u b}$ vs. $\Delta T_{\text {sub,i }}$ for an inner diameter of $3 \mathrm{~mm}$ with a heated length of $33 \mathrm{~mm}$ at inlet pressures of 818 $973 \mathrm{kPa}$

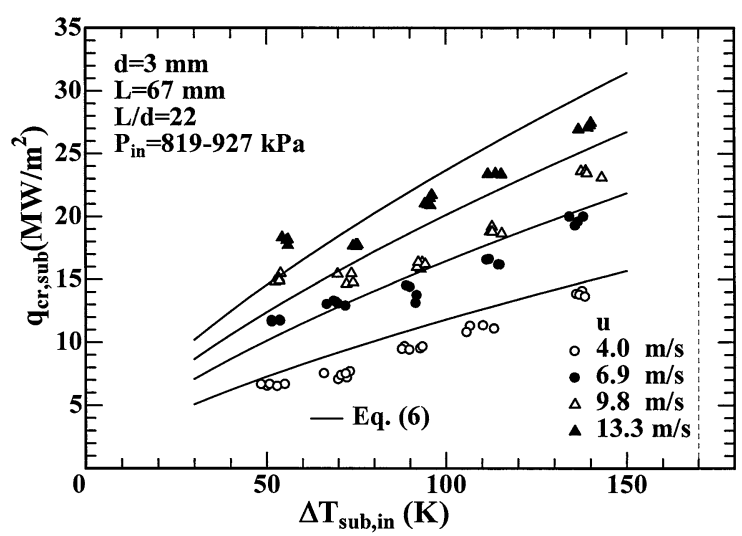

Fig. $14 q_{c r, s u b}$ vs. $\Delta T_{\text {sub,in }}$ for an inner diameter of $3 \mathrm{~mm}$ with a heated length of $67 \mathrm{~mm}$ at inlet pressures of $819-$ $927 \mathrm{kPa}$

\subsection{CHF against inlet subcooling}

Derivation of CHF correlation against inlet subcooling is useful to investigate the reliability of a divertor plate. Of course the relation between CHFs and inlet subcooling can be implicitly obtained for a given value of $L / d$ by solving the CHF correlation against outlet subcooling and the energy balance equation for the test tube. However explicit CHF correlation as a function of inlet subcooling is more convenient to use. We have given the CHF correlation against inlet subcooling.

The relation between $q_{c r, s u b}$ and $\Delta T_{\text {sub,out }}$ shown in Figs. 3 to 6 are rewritten on $q_{c r, s u b}$ vs. $\Delta T_{s u b, \text { in }}$ graph in Figs. 13 to 16 to know the influence of $\Delta T_{\text {sub, in }}$ on CHF for flow velocities from 4.0 to $13.3 \mathrm{~m} / \mathrm{s}$. The inlet subcooling, $\Delta T_{\text {sub,in }}$, was obtained by the measured inlet liquid temperature, $T_{i n}$, and inlet pressure, $P_{i n}$. The CHFs first decrease to the minimum CHF at the $\Delta T_{\text {sub,in }}$ of around $50 \mathrm{~K}$, and then increase with an increase in $\Delta T_{\text {sub,in }}$. The increasing rate becomes also lower for higher $\Delta T_{\text {sub,in }}$. The values of CHF data show nearly the same trends of dependence on $\Delta T_{\text {sub,out }}$, although the value of $\Delta T_{\text {sub,in }}$ at minimum CHF point is far higher than that of $\Delta T_{\text {sub,out }}$. 


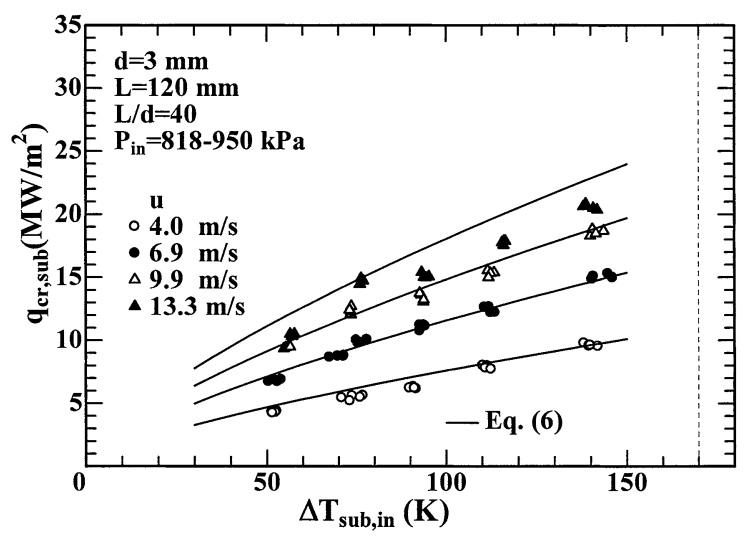

Fig. $15 q_{c r, s u b}$ vs. $\Delta T_{\text {sub,in }}$ for an inner diameter of $3 \mathrm{~mm}$ with a heated length of $120 \mathrm{~mm}$ at inlet pressures of 818 $950 \mathrm{kPa}$

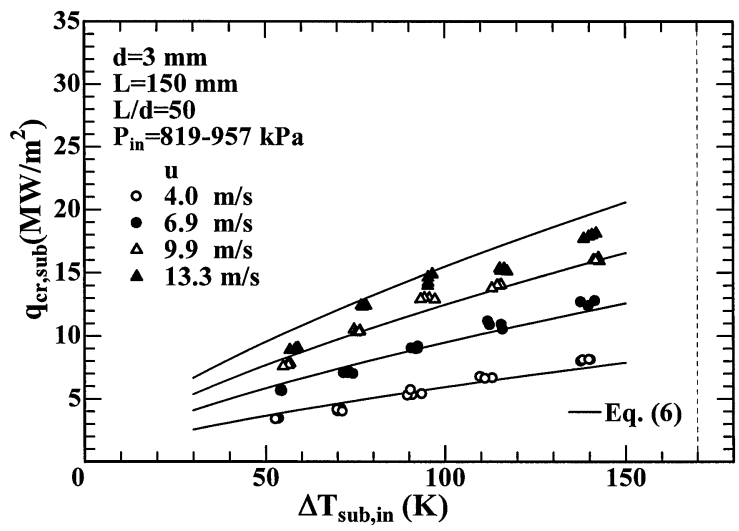

Fig. $16 q_{c r, s u b}$ vs. $\Delta T_{\text {sub,in }}$ for an inner diameter of $3 \mathrm{~mm}$ with a heated length of $150 \mathrm{~mm}$ at inlet pressures of 819 $957 \mathrm{kPa}$

3.3.1 Influence of $\boldsymbol{L} / \boldsymbol{d} \quad$ Figures 17 to 20 show the influence of the $L / d$ on the CHF for the inner diameter of 3,6, 9 and $12 \mathrm{~mm}$ at fixed inlet subcooling of 130, 130, 135 and $110 \mathrm{~K}$, respectively. The $q_{c r, s u b}$ for the ranging from 4.08 to 50 were shown versus the $L / d$ with the flow velocity as a parameter. As shown in Fig. 17, the values of $q_{c r}$ for a fixed value of inlet subcooling and flow velocity become exponentially lower with the increase in $L / d$. As mentioned above the CHFs against inlet subcooling can be implicitly obtained for a given value of $L / d$ by solving the CHF correlation against outlet subcooling, Eq. (4), and the energy balance equation for the test tube given as,

$$
\begin{aligned}
\Delta T_{\text {sub }, \text { out }} & =T_{\text {sab }, \text { out }}-\left(T_{\text {out }}\right)_{\text {cal }} \\
& =T_{\text {sab }, \text { out }}-\left(T_{\text {in }}+\frac{4 L q_{\text {cr,sub }}}{u c_{p l} \rho_{l} d}\right)
\end{aligned}
$$

Thermo-physical properties were evaluated at the temperature of $\left\{T_{\text {in }}+\left(T_{\text {out }}\right)_{\text {cal }}\right\} / 2$. The values of $q_{\text {cr }}$ obtained implicitly from Eqs. (4) and (5) are shown as each symbol in Figs. 17 to 20 for comparison. The CHF data for $L / d$ ranging from 4.08 to 50 are in good agreement with the values obtained implicitly by these equations.

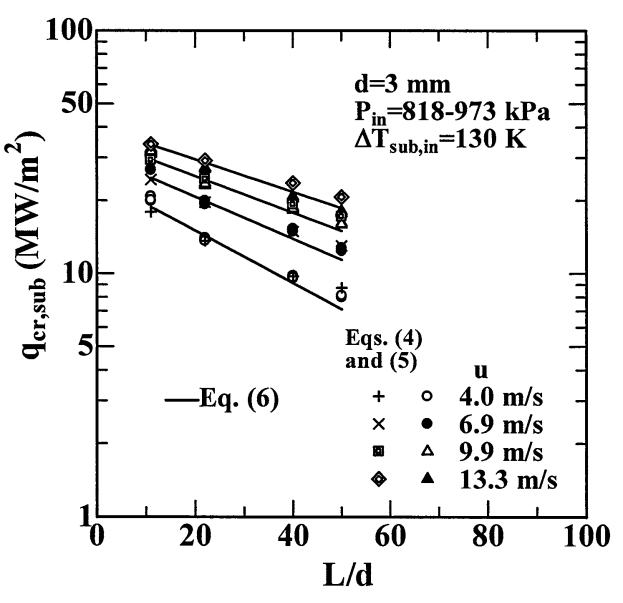

Fig. $17 q_{c r, s u b}$ vs. $L / d$ for an inner diameter of $3 \mathrm{~mm}$ at $\Delta T_{\text {sub,in }}$ of $130 \mathrm{~K}$ with the flow velocity of 4.0, 6.9, 9.9 and $13.3 \mathrm{~m} / \mathrm{s}$

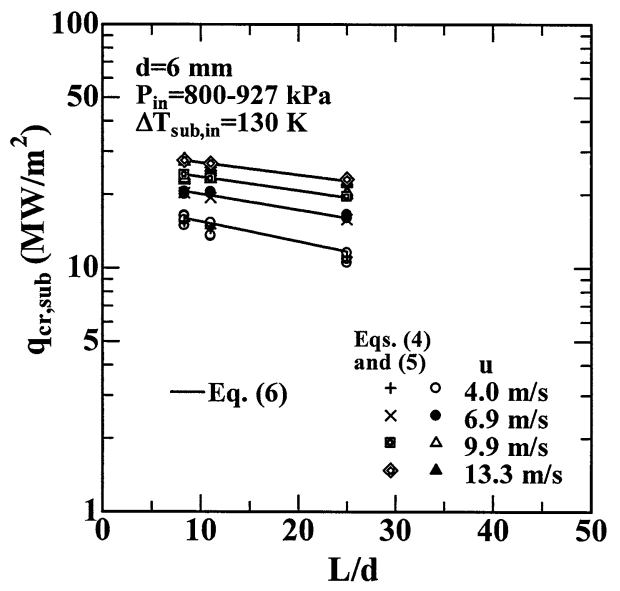

Fig. $18 q_{c r, s u b}$ vs. $L / d$ for an inner diameter of $6 \mathrm{~mm}$ at $\Delta T_{\text {sub,in }}$ of $130 \mathrm{~K}$ with the flow velocity of 4.0, 6.9, 9.9 and $13.3 \mathrm{~m} / \mathrm{s}$

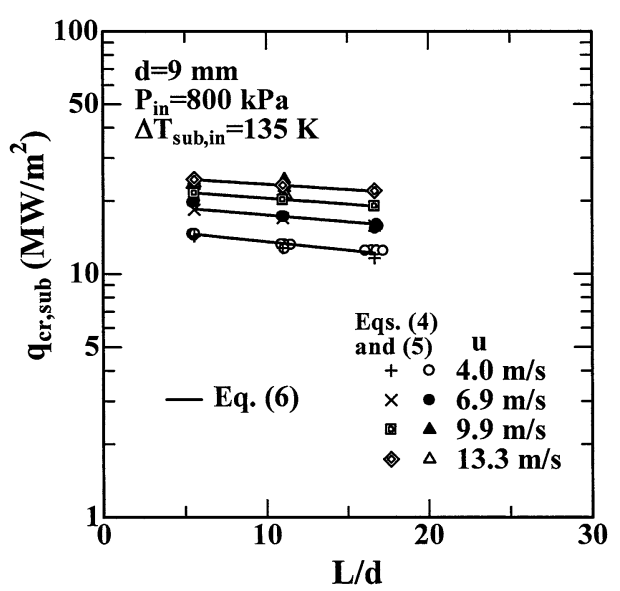

Fig. $19 q_{c r, s u b}$ vs. $L / d$ for an inner diameter of $9 \mathrm{~mm}$ at $\Delta T_{\text {sub,in }}$ of $135 \mathrm{~K}$ with the flow velocity of 4.0, 6.9, 9.9 and $13.3 \mathrm{~m} / \mathrm{s}$ 


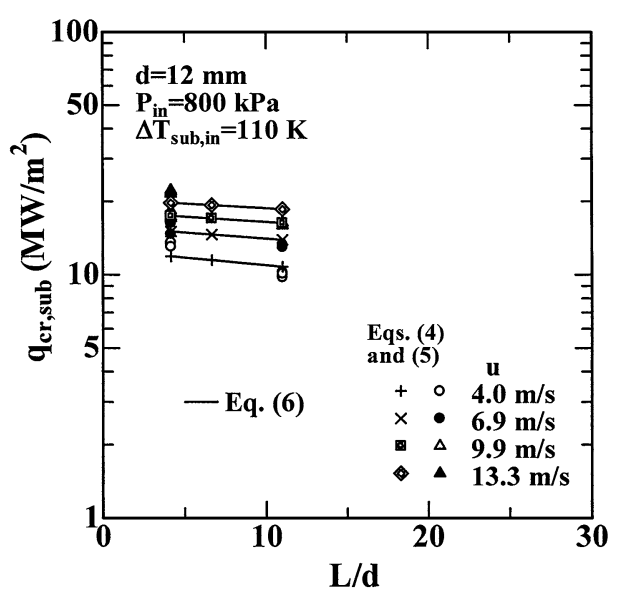

Fig. $20 q_{c r, s u b}$ vs. $L / d$ for an inner diameter of $12 \mathrm{~mm}$ at $\Delta T_{\text {sub,in }}$ of $110 \mathrm{~K}$ with the flow velocity of $4.0,6.9,9.9$ and $13.3 \mathrm{~m} / \mathrm{s}$

3.3.2 CHF correlation The CHF correlation against inlet subcooling for wide $L / d$ range $(4.08<L / d<$ 50 ) is derived as follows based on the effects of $L / d$ clarified in this work.

$$
\begin{aligned}
B o= & 0.082\left\{\frac{d}{\sqrt{\sigma / g\left(\rho_{l}-\rho_{g}\right)}}\right\}^{-0.1} \\
& \times W e^{-0.3}\left(\frac{L}{d}\right)^{-0.1} e^{-\frac{(L / d)}{0.53 R e^{0.4}}} S c^{* 0.7} \\
& \text { for inlet subcooling }\left(\Delta T_{\text {sub }, \text { in }} \geq 40 \mathrm{~K}\right)
\end{aligned}
$$

where, $S c^{*}$ is non-dimensional inlet subcooling, $S c^{*}=$ $c_{p l} \Delta T_{s u b, i n} / h_{f g}$. Saturated thermo-physical properties were evaluated at the outlet pressure, $\left(P_{\text {out }}\right)_{c a l}$. The value of the $\left(P_{\text {out }}\right)_{\text {cal }}$ is evaluated from the following equations $^{(10)}$.

$$
\begin{aligned}
& \left(P_{\text {out }}\right)_{\text {cal }}=P_{i p t}-\lambda \frac{\left(L+L_{i p t}\right)}{d} \frac{G^{2}}{2 \rho_{l}} \\
& \lambda=4\left(0.2295+0.6074 \frac{d}{L}\right) R e^{\left(-0.3305-0.02154 \frac{d}{L}\right)}
\end{aligned}
$$

where $L_{i p t}$ is the distance between the inlet pressure transducer and the inlet of the heated length and $\lambda$ is the friction factor for smooth tube.

The curves derived from Eq. (6) at each flow velocity are shown in Figs. 13 to 20 for comparison. The CHF data for $\Delta T_{s u b, \text { in }} \geq 40 \mathrm{~K}$ are in good agreement with the values given by the correlation. And further, this correlation can describe not only the CHFs obtained in this work for the inner diameter of 3 and $6 \mathrm{~mm}$ at the inlet pressure ranging from 753 to $995 \mathrm{kPa}$ but also the authors' published CHFs data (1 611 points) for the wide ranges of $P_{i n}=159 \mathrm{kPa}$ to $1 \mathrm{MPa}, d=3$ to $12 \mathrm{~mm}, L=33$ to $150 \mathrm{~mm}, \Delta T_{\text {sub, in }}=10$ to $151 \mathrm{~K}$ and $u=4.0$ to $13.3 \mathrm{~m} / \mathrm{s}$ within $15 \%$ difference for $40 \mathrm{~K} \leq \Delta T_{\text {sub,in }} \leq 150 \mathrm{~K}$ as shown in Fig. 21 .

3.3.3 Comparison of our correlation with other workers' CHF data The values derived from the correlation against the inlet subcooling are compared

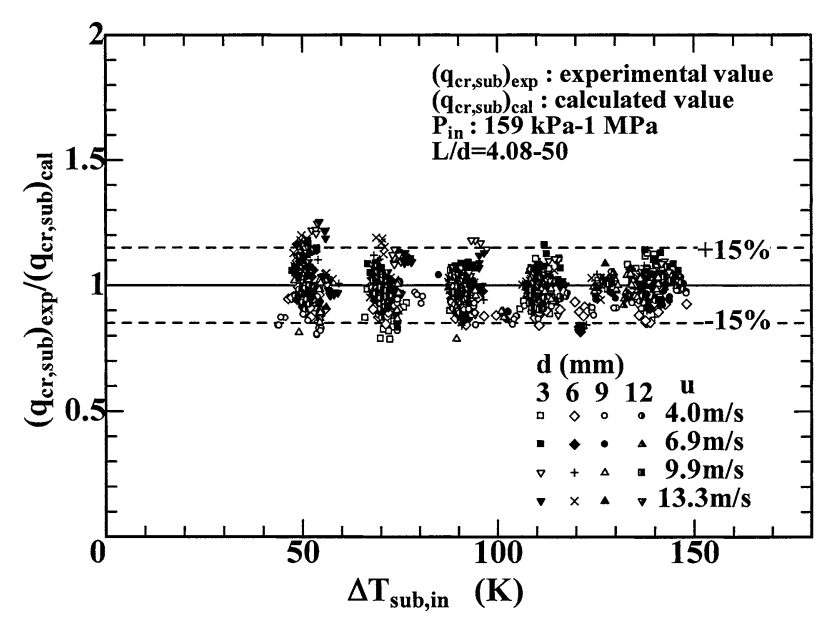

Fig. 21 Ratio of CHF data for the inner diameter of 3, 6, 9 and $12 \mathrm{~mm}$ to the values derived from the inlet CHF correlation versus $\Delta T_{\text {sub,in }}$ at inlet pressures of $159 \mathrm{kPa}-$ $1 \mathrm{MPa}$

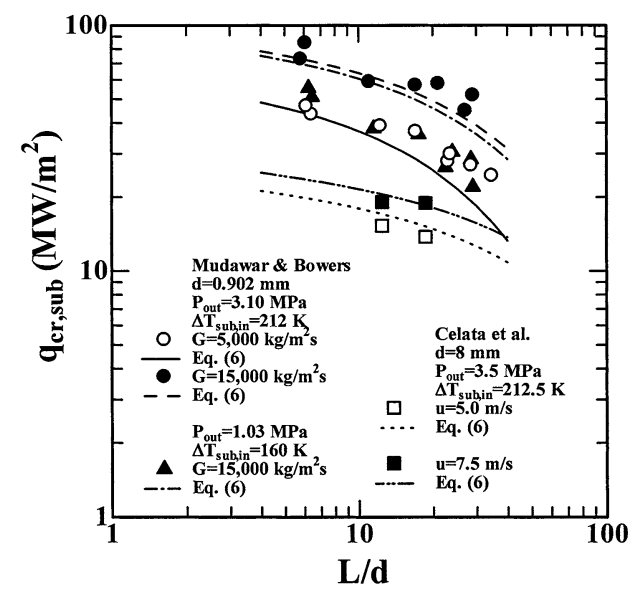

Fig. 22 Comparison of the values derived from the inlet CHF correlation with other workers' CHF data

with other workers' experimental data ${ }^{(11),(12)}$ with $d, P_{\text {out }}$, $\Delta T_{\text {sub,in }}, G$ and $u$ as a parameter in Fig. 22. The experimental data for $d=8 \mathrm{~mm}$ by Celata et al. agree well the values derived from the correlation. Those by Mudawar and Bowers show nearly the same trend of dependence on $L / d$, although those for only $P_{\text {out }}=1.03 \mathrm{MPa}$ are about $20 \%$ lower than the correlation in this experimental range.

\section{Conclusions}

The critical heat fluxes (CHFs) of subcooled water flow boiling are systematically measured for the innerdiameter $(d=3$ and $6 \mathrm{~mm})$ and the heated lengths $(L=67$, 120 and $150 \mathrm{~mm}$ ) with $L / d=22$ to 50 , the flow velocities ( $u=4.0$ to $13.3 \mathrm{~m} / \mathrm{s})$, the inlet subcoolings $\left(\Delta T_{\text {sub }, \text { in }}=48\right.$ to $148 \mathrm{~K})$, the outlet subcoolings $\left(\Delta T_{\text {sub,out }}=10.5\right.$ to $\left.95.1 \mathrm{~K}\right)$, the inlet pressure $\left(P_{\text {in }}=753\right.$ to $\left.995 \mathrm{kPa}\right)$ and the outlet pressure $\left(P_{\text {out }}=720\right.$ to $\left.887 \mathrm{kPa}\right)$. Experimental results lead to the following conclusions.

(1) The CHFs first decrease to the minimum CHF 
at $\Delta T_{\text {sub,in }}$ of around $50 \mathrm{~K}$ and $\Delta T_{\text {sub,out }}$ of around $30 \mathrm{~K}$, and then increase with an increase in the subcooling. The increasing rate becomes lower for higher subcooling.

(2) The CHFs become linearly lower with the increase in the $L / d$ at a fixed $d$ and $\Delta T_{\text {sub,out }}$. The slope on the log-log graph kept almost constant about -0.1 with the flow velocity ranging from 4.0 to $13.3 \mathrm{~m} / \mathrm{s}$ except for the experimental data at $u=4.0 \mathrm{~m} / \mathrm{s}$ for $d=3 \mathrm{~mm}$.

( 3 ) The existing CHF correlation against outlet subcooling was modified to new one containing the $L / d$ effect based on these experimental data for wide $L / d$ range from 4.08 to 50 clarified in this work.

( 4 ) The CHF correlation against inlet subcooling for wide $L / d$ range $(4.08<L / d<50)$ is derived based on the effects of $L / d$ clarified in this work to investigate the reliability of a divertor plate.

( 5 ) The correlations against outlet and inlet subcooling can describe not only the CHFs obtained in this work for the inner diameter of 3 and $6 \mathrm{~mm}$ at the outlet pressure of around $800 \mathrm{kPa}$ but also the authors' published CHFs data (1611 points) for the wide ranges of $P_{\text {in }}=$ $159 \mathrm{kPa}$ to $1 \mathrm{MPa}, d=3$ to $12 \mathrm{~mm}, L=33$ to $150 \mathrm{~mm}$ and $u=4.0$ to $13.3 \mathrm{~m} / \mathrm{s}$ within $15 \%$ difference for $30 \mathrm{~K} \leq$ $\Delta T_{\text {sub,out }} \leq 140 \mathrm{~K}$ and $40 \mathrm{~K} \leq \Delta T_{\text {sub,in }} \leq 151 \mathrm{~K}$.

\section{Acknowledgements}

This work was carried out by the LHD Joint Research Program of NIFS (National Institute for Fusion Science) Japan.

\section{Appendix A: Entrance Length for Test Tube}

For turbulence flow, the tube length in which the center line velocity reaches $99 \%$ of the maximum value is correlated by the following equation ${ }^{(13)}$.

$$
\frac{L_{e}}{d}=0.693 R e^{1 / 4}
$$

where $L_{e}$ is the entrance length.

Reynolds numbers, $R e$, for the test tube inner diameters $(d=3$ to $12 \mathrm{~mm})$ in this work and others ${ }^{(1)-(5)}$ are given in the range of $4 \times 10^{4}$ to $10^{6}$ with the flow velocities $(u=4.0$ to $13.3 \mathrm{~m} / \mathrm{s})$ at the inlet pressures $\left(P_{\text {in }}=159 \mathrm{kPa}\right.$ to $1 \mathrm{MPa})$. The ratios of the entrance length to the test

Table 1 Entrance lengths for 3, 6, 9 and $12 \mathrm{~mm}$ inner diameter test sections in the experimental water loop

\begin{tabular}{|l|l|l|}
\hline$d(\mathrm{~mm})$ & $L_{e}$ & $L_{e} / d$ \\
\hline 3 & 240 & 80 \\
\hline 6 & 333 & 55.5 \\
\hline 9 & 333 & 37 \\
\hline 12 & 333 & 27.75 \\
\hline
\end{tabular}

tube inner diameter, $L_{e} / d$, are obtained ranging from 9.8 to 21.9 by Eq. (9).

The entrance lengths for 3, 6, 9 and 12-mm inner diameter test sections in the experimental water loop are shown in Table 1 respectively. The values of $L_{e} / d$ for these test sections are enough larger than those calculated from Eq. (9), which are necessary to form fully developed flow profile.

\section{References}

( 1 ) Hata, K., Fukuda, K., Shiotsu, M., Sakurai, A., Noda, N., Motojima, O. and Iiyoshi, A., Critical Heat Fluxes in Subcooled Boiling of Water Flowing Upward in a Vertical Tube for Wide Ranges of Liquid Velocity, Subcooling and Pressure, Proceedings of 6th International Conference on Nuclear Engineering, Paper No. ICONE-6362, (1998), pp.1-16.

( 2 ) Hata, K., Fukuda, K., Shiotsu, M. and Sakurai, A., The Effect of Diameter on Critical Heat Flux in Vertical Heated Short Tubes of Various Inside Diameters Cooled with an Upward Flow of Subcooled Water, Ninth International Topical Meeting on Nuclear Reactor Thermal Hydraulics, (1999), pp.1-20.

( 3 ) Sato, G., Hata, K., Shiotsu, M. and Noda, N., Critical Heat Fluxes on Short Vertical Tube Inner Surface in Water Flowing Upward (Effect of tube Inner Diameter and Application to Thermal Analysis of Divertor Plate), Proceedings of 8th International Conference on Nuclear Engineering, Paper No. ICONE-8126, (2000), pp.1-12.

(4) Hata, K., Sato, T. and Shiotsu, M., Influence of Tube Length on Critical Heat Fluxes in Water Flowing Upward, Proceedings of 9th International Conference on Nuclear Engineering, Paper No. ICONE-9569, (2001), pp.1-12.

( 5 ) Hata, K., Sato, T., Tanimoto, T., Shiotsu, M. and Noda, N., Critical Heat Fluxes of Subcooled Water Flow Boiling against Outlet Subcooling in Short Vertical Tube, Proceedings of the 10th International Conference on Nuclear Engineering, Paper No. ICONE1022324, (2002), pp.1-10.

( 6 ) Celata, G.P., Critical Heat Flux in Subcooled Flow Boiling, Heat Transfer 1998, Proceedings of 11th International Heat Transfer Conference, Vol.1, (1998), pp.261-277.

( 7 ) Bergles, A.E., Subcooled Burnout in Tubes of Small Diameter, ASME Paper No. 63-WA-182, (1963), pp.19.

( 8 ) Nariai, H., Inasaka, F. and Shimura, T., Critical Heat Flux of Subcooled Flow Boiling in Narrow Tube, Proceedings of the 1987 ASME-JSME Thermal Engineering Joint Conference, Vol.5, Hemisphere, New York, (1987), pp.455-462.

( 9 ) Vandervort, C.L., Bergles, A.E. and Jensen, M.K., An Experiment Study of Critical Heat Flux in Very High Heat Flux Subcooled Boiling, International Journal of Heat and Mass Transfer, Vol.37, Suppl. 1 (1994), pp.161-173.

(10) Hall, D.D. and Mudawar, I., Ultra-High Critical Heat 
Flux (CHF) for Subcooled Water Flow Boiling-II: High-CHF Database and Design Equation, International Journal of Heat and Mass Transfer, Vol.42 (1999), pp.1429-1456.

(11) Celata, G.P., Cumo, M. and Mariani, A., Enhancement of CHF Water Subcooled Flow Boiling in Tubes Using Helically Coiled Wires, International Journal of Heat and Mass Transfer, Vol.37, No.1 (1994), pp.53-67.
(12) Mudawar, I. and Bowers, M.B., Ultra-High Critical Heat Flux (CHF) for Subcooled Water Flow Boiling-I: CHF Data and Parametric Effects for Small Diameter Tubes, International Journal of Heat and Mass Transfer, Vol.42 (1999), pp.1405-1428.

(13) Brodkey, R.S. and Hershey, H.C., Transport Phenomena, (1988), p.568, McGraw-Hill, New York. 